\title{
Seizures Following Intracranial Surgery: Incidence in the First Post-Operative Week
}

\author{
E. MATTHEW, A.L. SHER WIN, S.A. WELNER, K. ODUSOTE and J.G. STRATFORD
}

SUMMARY: Consecutive craniotomies (1/8) draw'n from major hospitals, and performed for disorders other than epilepsy. or acute trauma were reviewed. The final diagnosis included tumor (70), subdural hematoma (13), aneurysm (10), arteriovenous malformation (7), and miscellaneous lesions (18). Eighty-seven (73.7\%) patients had not experienced seizures prior to neurosurgery, ll of these (12.6\%) had a seizure within the first week, in six the attack occurred within 24 hours, and of these three had further attacks. In contrast, of the 31 patients (26.3\%) that had one or more seizures prior to operation, II patients $(35.5 \%)$ had seizures within the first week. In ten patients seizures occurred within the first 24 hours and of these seven

RESUME: Les auteurs ont revu cent dix-huit (118) cas consécutifs de craniotomies effectuées dans le traitement de pathologies excluant épilepsie et trauma crânien aigu. Ces cas provenaient de deux hôpitaux généraux et incluaient: tumeur (70), hématome sous-dural (13), anévrysme (10). malformation artério-veineuse (7), lésions diverses (18).

Quatre-vingt-sept (87) patients (73.7\%) n'avaient jamais présenté de crise avant l'intervention. Parmi ces derniers, Il (12.6\%) présentèrent une crise la première semaine, et 6 durant les premières 24 heures post-opératoires. Trois (3) d'entre eux présentèrent également des crises par la suite.

Par contre, parmi les 31 patients (26.3\%) qui avaient présenté une ou plusieurs crises avant l'intervention, 11 patients $(35.5 \%)$ présentèrent des crises durant la première semaine, dont 10 durant les premières 24 had one or more recurrences later in the week. Anticonvulsant drugs were administered to 72 patients before operation, including all those with a history of seizures, but loading doses were not utilized to ensure therapeutic levels. In patients with predisposing factors to postoperative seizures, anticonvulsant drugs should be administered before or immediately following craniotomy in adequate dosage to rapidly achieve and maintain effective plasma levels. Phenytoin, owing to its minimal sedative effects is the drug of choice. A loading dose of 18 milligrams per kilogram can be safely administered as an admixture to an intravenous infusion of $0.9 \%$ saline with careful monitoring of cardiopulmonary function.

heures. Parmi ces 10 derniers patients, 7 eurent de nouvelles crises au cours de la semaine suivant l'intervention.

Avant l'intervention chirurgicale, des médicaments anticonvulsivants avaient été administrés à 72 patients y compris à ceux qui avaient déjà présenté des crises. Toutefois, la dose initiale n'assurait pas toujours un niveau thérapeutique.

Chez les patients prédisposés aux convulsions postopératoires, les traitements anticonvulsivants doivent être administrés avant et immédiatement après la craniotomie selon un dosage suffisant pour atteindre rapidement et pour maintenir des niveaux plasmatiques efficaces. Le phen.toin, à cause de ses effets sédatifs minimes, est le médicament de choix dans ce cas. Une dose initiale de $18 \mathrm{mg} / \mathrm{kg}$ peut être administrée sans danger dans une perfusion $i$.v. de salin de $0.9 \%$ sous contrôle cardiopulmonaire constant.
From the Department of Neurology and Neurosurgery, McGill University, Mont real General Hospital, and Montreal Neurological Institute.

Supported by grants from the Medical Research Council of Canada (MT-145I) and the Savoy Foundation.

Reprint requests to Dr. A.L. Sherwin, Montreal Neurological Institute, 380 I University St., Montréal, Québec, H3A 2B4, Canada.
Patients operated on for intracranial lesions may subsequently develop seizures or may continue to have attacks from which they suffered preoperatively. Cushing and Eisenhardt (1923) reported that 35 percent of their patients with meningiomas had seizures after surgery. Penfield and Erickson (1941) noted that nine of 21 patients with convexity meningiomas, eight of 33 patients with brain abscess and three of six patients with supratentorial astrocytomas without pre-operative seizures developed epilepsy postoperatively. In a review of epilepsy occurring for the first time after brain tumor surgery, Ketz (1974) concluded that the incidence was about two percent for gliomas and 3-16\% for meningiomas. For other intracranial lesions, the incidence seemed highest in survivors after operative treatment of pyogenic abscess. This varied from 41-56\% (Horwitz and Rizzoli, 1967), but may be as high as $72 \%$ (Prior et al, 1973). A $16 \%$ incidence of postcraniotomy epilepsy has been reported for angiomas (Patterson and McKissock, 1956) while Cabral et al (1976) reported seizures in $22 \%$ of patients treated for intracranial aneurysm.

The pathophysiology of postoperative seizures may be similar to that which occurs in patients after head injury. Jennett (1969) described the seizures which occur during the first week after trauma as "early traumatic epilepsy" and concluded that these seizures differ from those occurring in subsequent weeks. There has been some controversy about the need for special consideration of such seizures. However, Jennett and Lewin (1960) and Jennett (1962, 1969, 1975) have shown that the risk of developing recurrent seizures (epilepsy) is four times greater in patients who have early seizures. 'Early' seizures may therefore be of prognostic significance 
in the development of 'late' seizures, a genetically determined constitutional tendency towards a lower seizure threshold being a common factor in both types of epilepsy (Caveness, et al, 1979).

The present study was initiated to establish the incidence of seizures in the first week after craniotomy, to identify the factors which predispose to such seizures, to determine if there is a parallel between the pattern of such seizures and the 'early' seizures which occur after craniocerebral trauma, and to outline a regimen of pharmacological prophylaxis.

\section{METHODS}

The sampling system was devised to ascertain the incidence of seizures in the first post-operative week in patients who underwent intracranial surgery. A total of 118 consecutive patients who underwent craniotomy for disorders other than acute trauma or epilepsy were drawn from two major hospitals over a six month period (Figure 1). The patients were divided into two groups based on the presence or absence of pre-operative seizures. Group A consisted of 87 patients, 43 males and 44 females without preoperative seizures. Group B consisted of 31 patients, 21 males and 10 females who had pre-operative seizures. The mean age for Group $A$ was 51.4 years and 44.4 years for Group B. The final diagnoses included tumor, arteriovenous malformation, aneurysm, and subdural hematoma (Table 1).

In an effort to identify predisposing factors, special attention was paid to the site of the lesion and post-operative complications such as metabolic derangements of infection. All patients were operated upon under general anaethesia (mean duration 5.4 hours; range, 3-8 hours) and received steroids during the post-operative period. Perioperative drug therapy was reviewed with special emphasis on anticonvulsant drugs. In Group A, eight patients received anticonvulsant drugs prior to operation, while in 33 patients, the medication was commenced immediately after surgery. The remaining 46 patients did not receive anticonvulsants though seven patients were placed on medication following their first seizure. All 31 patients in Group B received anticonvulsant drugs before and after surgery. Drugs utilized included: phenytoin (oral or intravenous) usually in combination with phenobarbital (15 patients in Group A, 20 patients in Group B); carbamazepine ( 7 patients in Group B) or primidone (4 patients in Group B). As this was a retrospective study the investigators had no influence on the nature or dosage of the anticonvulsant drugs administered. Patients with post-operative seizures were subjected to careful scrutiny to identify possible predisposing factors.

\section{RESULTS}

Eleven patients (12.6\%) in Group A and 11 patients $(35.5 \%)$ in Group B had seizures during the first postoperative week. Table 2 provides details of the lesions, sites and time of occurrence of the seizures in Group A. Focal motor seizures affecting somatic regions corresponding to the cerebral areas involved by the surgical procedure, occurred in ten $(81.8 \%)$ of 11 patients. In one patient, the seizure was described as generalized, however, the onset was not observed. Only one of the 11 patients with post-operative seizures in Group A had pre-operative anti-convulsant therapy. This patient received phenobarbital, 30 milligrams twice daily, however, it was discontinued three days prior to surgery. Anticonvulsant drug therapy was reinstituted following a seizure on the fifth post-operative day. Four other patients received anticonvulsant drugs immediately after operation. This took the form of intravenous or oral phenytoin in doses of 100 milligrams eight-hourly, with or without $60 \mathrm{mg}$ of phenobarbital. Plasma drug levels were not determined in a systematic fashion. Seizures occurred during the first 24 hours of the post-operative period in two of these patients, and recurred during the first week in one patient; the other two patients had seizures during the first week.

Table 3 outlines the details of the seizures in Group B which were focal and motor in all patients, and as in Group A, affected somatic regions corresponding to the cerebral areas involved in the surgical procedure. In six patients, the focal seizures became secondarily generalized. All except one patient had seizures during the first twenty-four hours of the postoperative period, and in six of these, the seizures recurred one or more times during the first week. All patients received anticonvulsant drugs before

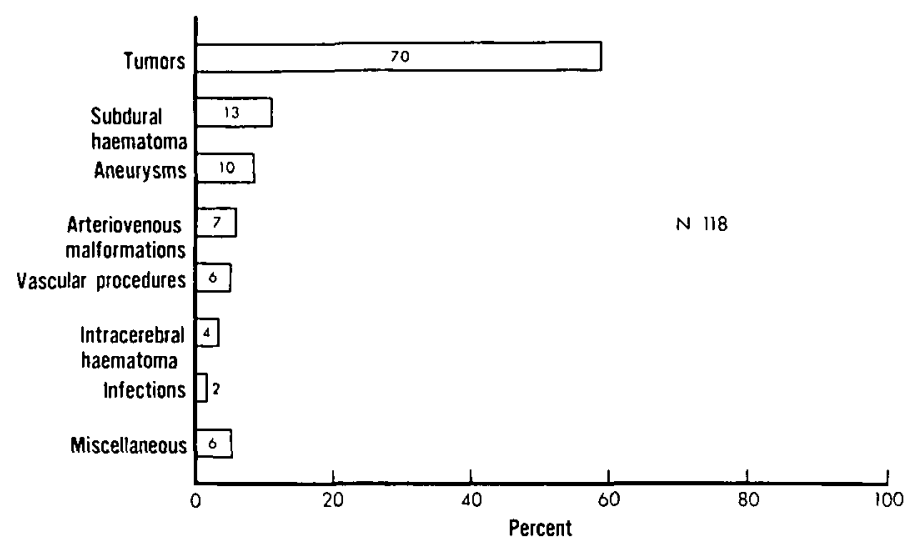

Figure $I$ - Distribution of lesions in patients undergoing craniotomy.
Effect of Anticonvulsant Drugs (ACD) on Incidence of Post-Operative Seizures

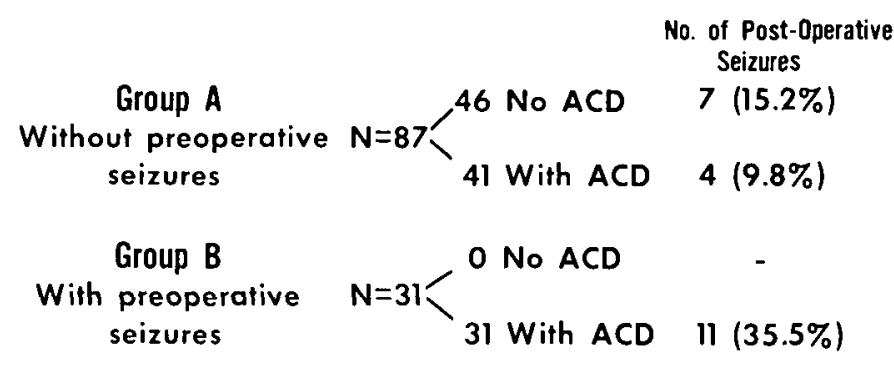

Figure 2 - Effect of anticonvulsant drugs (ACD) on incidence of post-operative seizures. 
TABLE 1

Incidence of Post-operative Seizures

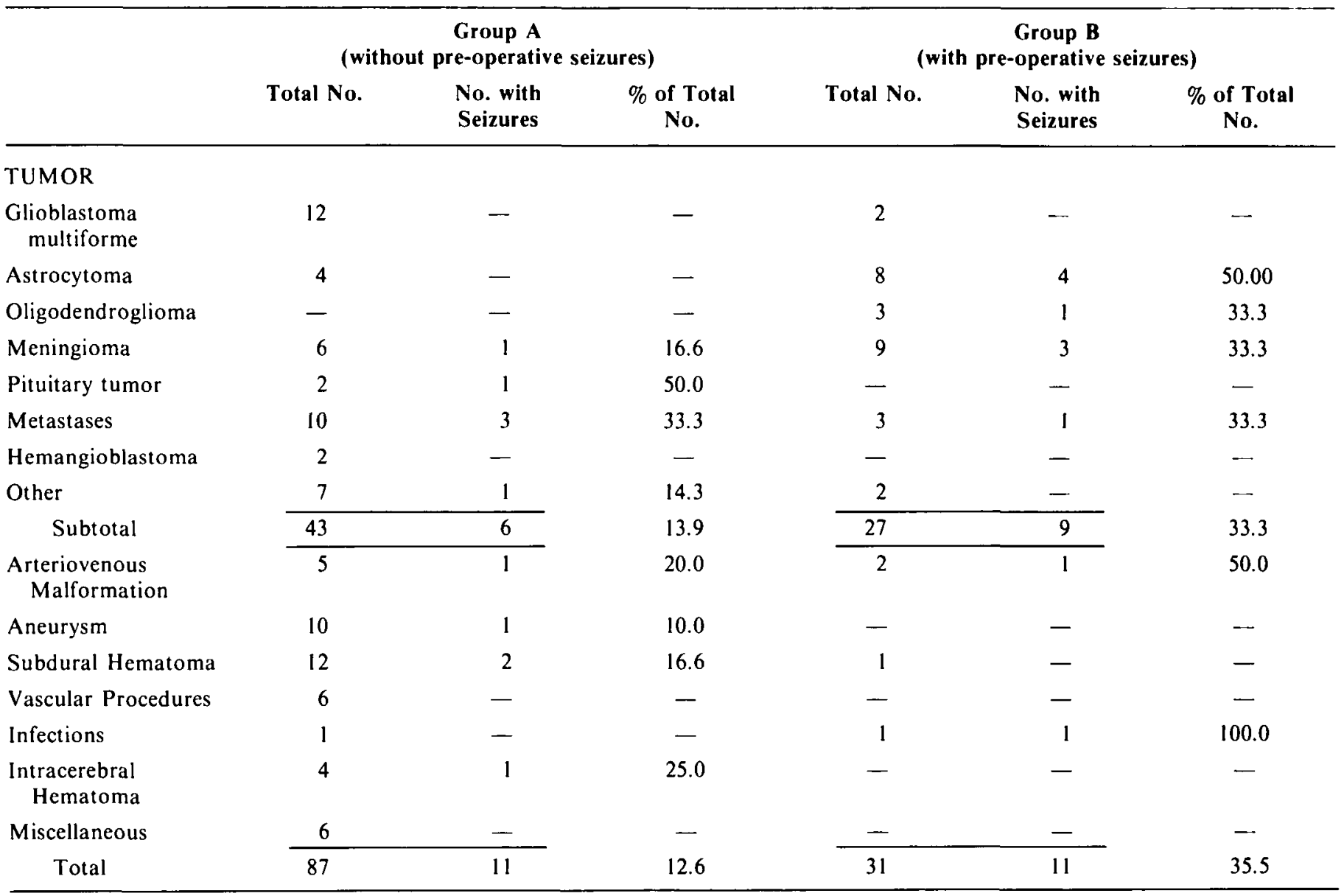

and immediately after operation.

The effect of anticonvulsant medication instituted immediately following operation on the incidence of 'early' post-operative seizures is summarized in Figure 2. In Group A, though the incidence is lower in patients who had prophylactic treatment, the difference is not statistically significant.

\section{DISCUSSION}

These results indicate that seizures occurred in the first post-operative week in $12.6 \%$ of the patients who had no pre-operative seizures. This incidence is slightly higher than the $3.9 \%$ reported after surgery for intracranial aneurysms (Cabral et al, 1976b) and $8.9 \%$ following transtentorial approach for removal of acoustic nerve tumors (Cabral et al, 1976a). The pathology in our series was, however, more varied, and this could account for the difference.

In patients with a history of seizures prior to surgery, the incidence of postoperative seizures was three times higher $(35.5 \%)$. One third of the patients with tumors in this group had seizures. This included half of the patients with astrocytomas and a third each of the patients with oligodendrogliomas, meningiomas, and metastases. Of the patients with other lesions, only two had post-operative seizures.

The majority of the patients in both groups had their seizures during the first twenty four hours. In several of these, anticonvulsant therapy had been instituted immediately after the surgery. Though plasma anticonvulsant drug levels were not measured, from the dosage employed it would appear that effective levels were not attained with sufficient rapidity to protect the patients against seizures. The seizures usually originated in cerebral areas contiguous to the surgical procedure. In almost all instances, this included regions of the cerebral hemispheres in the vicinity of the sensorimotor strip.

Several factors predisposed to 'early seizures' in these patients. The occurrence of seizures prior to surgery clearly increased the risk of 'early' post-operative seizures. Similar observations were made by Prior et al (1973) who found that of their patients with meningiomas with a history of preoperative seizures, more than half had post-operative seizures one or more months after surgery. When the site of lesion and the areas of the brain involved by the surgical procedure included portions of the hemispheres, 
TABLE 2

Incidence of Post-operative Seizures in Patients without Pre-operative Seizures (Group A)

No. Site Time of occurrence Recurrence of

First 24 hrs First week seizures (1st week)

\section{TUMOR \\ Astrocytoma \\ Oligodendroglioma \\ Meningioma \\ Metastases \\ Pituitary tumor \\ Other}

\section{Subtotal}

ARTERIOVENOUS MALFORMATION ANEURYSM

SUBDURAL HEMATOMA

INFECTIONS

INTRACEREBRAL HEMATOMA

Total

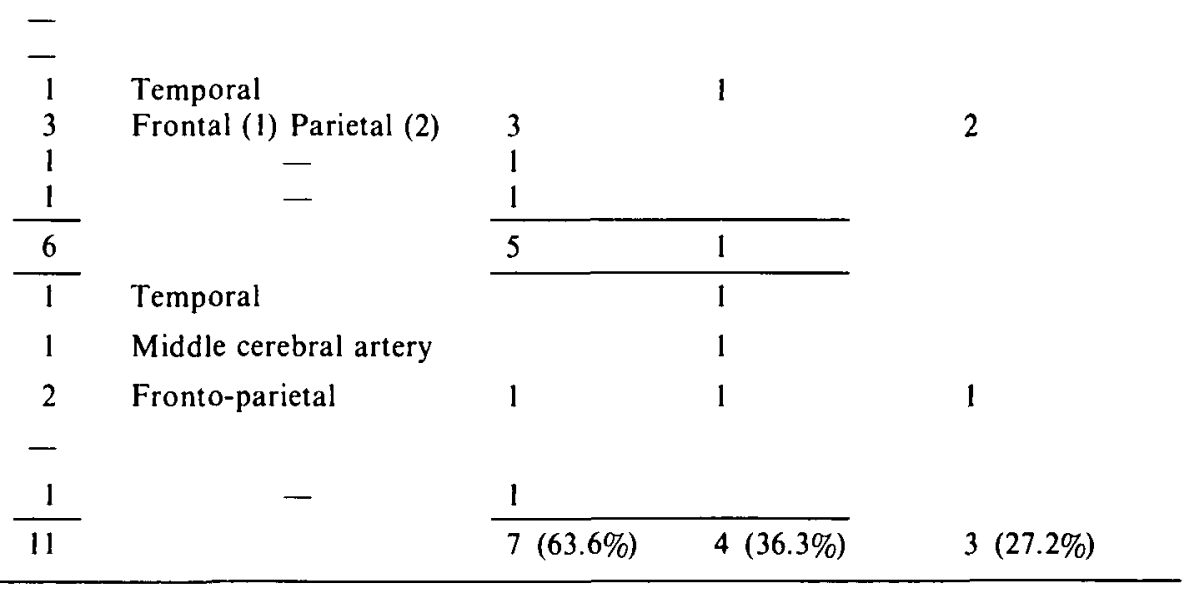

TABLE 3

Incidence of Post-operative Seizures in Patients with Pre-operative Seizures (Group B)

\section{TUMOR}

Astrocytoma

Oligodendroglioma

Miningioma

Metastases

Pituitary

Other

Subtotal

ARTERIOVENOUS MALFORMATION

ANEURYSM

SUBDURAL HEMATOMA

INFECTIONS

INTRACEREBRAL HEMATOMA

Total
No. Site
Time of occurrence First 24 hrs First week
Recurrence of seizures (1st week)

\section{4}

1

Fronto-temporal

3 Fronto-temporal

Parietal (1) Frontoparietal (1) Olifactory groove (1)

Proovetal
Parietal

$\frac{1}{-}$

Fronto-parietal

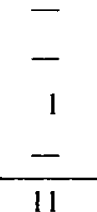

$\begin{array}{lll}4 & & 3 \\ 1 & 1 & 1 \\ 2 & 1 \\ 1 & & 1\end{array}$

\begin{tabular}{lll}
\hline 8 & 1 & 6 \\
\hline 1 & &
\end{tabular}

in particular the sensorimotor strip, the patients were at increased risk for "early" post-operative seizures. These findings are in accordance with observations of Penfield and Jasper (1954), and Anderson and Lomo (1969). Seizures occurred most frequently in patients with tumors. However, patients with tumors constituted $60 \%$ of the total population included in the study, hence this may be a function of the sample.

When our data is compared to that derived from patients who developed seizures following cranio-cerebral trauma, the incidence of "early" postoperative seizures $(12.6 \%)$ is higher than the $5.0 \%$ observed by Jennett and Lewin (1960) and Jennett (1969) in patients with non-missile head injury.
When the comparison is carried further, however, some similarities emerge. In patients with post-operative seizures, $77.3 \%$ had their first attack within the first 24 hours. Following trauma, $61 \%$ of the "early" seizures occurred within 24 hours of the injury (Jennett, 1975; Russell, 1951) and were more common when the injury involved the sensorimotor area (Northfield, 
1973). Moreover, some focal features were observed in the majority of seizures occurring after craniotomy and head injury. It is therefore conceivable that the longterm followup of the patients included in the present study may yield results similar to the data now available with regard to post-traumatic epilepsy.

The recent data pertaining to the "kindling" phenomenon (Goddard et al, 1969; Wada and Osawa, 1976) raises the possibility that recurrent seizures could be avoided by preventing the initial seizure. There is some controversy, however, about the use of prophylactic anticonvulsant therapy. Caveness (1976) discussed this issue with reference to head injury and defined several problems which included the choice of the patients' drug regimens, and time of initiation of treatment. Rapport and Penry (1973) found considerable variation in the use of anticonvulsant drugs. Apart from the possibility that prevention of early seizures might reduce the likelihood of developing epliepsy, 'early' postoperative seizures might be hazardous to the patient. Status epilepticus can develop and seizures may precipitate secondary complications such as aspiration pneumonitis. Post-ictal neurological deficits, particularly if the seizure was not observed, could lead to unnecessary radiological and postoperative diagnostic procedures.

\section{OUTLINE OF SUGGESTED MANAGEMENT}

Phenytoin is the drug of choice since the sedative properties of phenobarbital may preclude its use during the peri-operative period. Phenytoin has minimal suppressant effect on the brain and patients remain alert and responsive following an adequate loading dose. In order to attain therapeutic plasma levels rapidly, phenytoin may be administered in a dose of 18 milligrams per kilogram intravenously. This will maintain plasma phenytoin levels above 10 micrograms per millilitre for twentyfour hours in most subjects (Cranford et al, 1978). Cloyde et al (1978) have shown that phenytoin is compatible as an admixture in small volumes of saline but not in five percent dextrose in water. They recommend the follow- ing technique to prepare a dilute solution of phenytoin for intravenous infusion (Cloyde et al, 1980): Start an intravenous line with a volume control set $\left(\right.$ Buretrol $^{(\mathrm{R})}$, Volutrol $\left.{ }^{(\mathrm{R})}\right)$; add five millilitres of 0.9 percent saline to the set to which is added the required amount of phenytoin sodium for injection. The resultant mixture is then diluted with 0.9 percent saline to produce a dilution of 20-30 milligrams of drug per millilitre of fluid (final volume: 25-75 millilitres). Because minor crystallization has been noted by some a 0.45 micron filter should be placed in the line. The use of an infusion pump ensures an accurate infusion rate which should not exceed 50 milligrams per minute. A slower initial infusion rate is recommended in elderly patients or those with unstable cardiopulmonary function. Hypotension is a more frequent complication than cardiac rhythm disturbances so it is advisable to check blood pressure, pulse and respiratory rates at 60second intervals for the first five minutes and every five minutes thereafter. Cardiac monitoring is desirable, while in elderly or debilitated patients, constant monitoring of the blood pressure is indicated.

In the case of elective neurosurgery, adequate plasma levels can be obtained by administering the same loading dose orally in divided doses. Nine milligrams per kilogram should be administered for two days followed by five milligrams per killogram as a daily maintenance dose. The administration of phenytoin intramuscularly is not recommended because absorption is slower and less complete (Booker, 1978).

Plasma phenytoin levels should be determined pre-operatively, on the first and third post-operative days and when indicated thereafter. Such monitoring is essential because of the known variability in the elimination of phenytoin which may be accentuated by the operative procedure. Prophylactic anticonvulsants should be continued during the immediate post operative period and then gradually discontinued if there are no seizures or epileptiform abnormalities on the electroencephalogram. In the latter case a more prolonged course of drug therapy may be warranted.

\section{REFERENCES}

ANDERSEN, P., LOMO, T. (1969). Organization and frequency dependence of hippocampal inhibitions. In: Basic Mechanisms of the Epilepsies. Ed. Jasper, H.H., Ward. A.A. and Pope A. Churchill, London. pp 604-609.

BOOKER, H.E. (1978). Clinical use and interpretation of serum phenytoin levels. In Antiepileptic Drugs. Qualitative Analysis and Interpretation. Ed. Pippenger. C.E.. Penry, J.K., and Kutt, H. Raven Press, New York. pp 253-260.

CABRAL, R., KING. T.T. and SCOTT, D.F. (1976). Epilepsy after two different neurosurgical approaches to the treatment of ruptured intracranial aneurysm. J. Neurol. Neurosurg. Psychiatry 39: 1054-1056.

CABRAL, R., KING, T.T. and SCOTT, D.F. (1976). Incidence of post-operative epilepsy after a transtentorial approach to acoustic nerve tumours. J. Neurol. Neurosurg. Psychiatry, 39: 663-665.

CAVENESS, W.F. (1976). Epilepsy, a Product of Trauma in our Time. Epilepsia, 17: 207. 215.

CAVENESS, W.F., MEIROWSKY, A.M., RISH, B.L., MOHR, J.P., KISTLER, J.P., DILLON, J.D. and WEISS, G.H. (1979). The nature of post-traumatic epilepsy. $J$. Neurosurg. 50: 545-553.

CLOYD, J.C., BOSCH, D.E. and SAWCHUK, R.J. (1978). Concentration-time profile of phenytoin after admixture with small volumes of intravenous fluids. Am. J. Hosp. Pharmacy 35: 45-48.

CLOYD, J.C., GUMNIT, R.J. and McLAIN, JR, L.W. (1980). Intravenous phenytoin in the management of status epilepticus. J. Amer. Med. Ass. (In Press)

CRANFORD, R.E., LEPPIK, I.E., PATRICK, B., ANDERSON, C.B. and KOSTICK, B. (1978). Intravenous phenytoin: Clinical and pharmacokinetic aspects. Neurology, 28: 874-880.

CUSHING, H. and EISENHARDT, L. (1938). Meningiomas. Charles C. Thomas, Springfield, Illinois, pp 875.

GODDARD, G.V., MACINTYRE, D.C. and LEECH, C.K. (1969). A permanent change in brain function resulting from daily electrical stimulation. Exptl. Neurol. 25: 295-330.

HOR WITZ, N.H., RIZZOLI, H.V. (1967), Postoperative complications in Neurosurgical Practice. The Williams and Wilkins Company. Baltimore, pp 196-198.

JENNETT, W.B. (1962). Epilepsy after Blunt Head Injuries. William Heinemann Medical Books, London. pp 150.

JENNETT, W.B. (1969). Early traumatic epilepsy. Lancet 1: 1023-1025.

JENNETT, W.B. (1975). Epilepsy after NonMissile Head Injuries. William Heinemann Medical Books, Chicago. pp 179

JENNETT, W.B., LEWIN, W. (1960). Traumatic Epilepsy after Closed Head Injuries. J. Neurol. Neurosurg. Psychiat. 23: 295-301.

KETZ, E. (1974). Brain Tumor and Epilepsy. In: Handbook of Clinical Neurology. Vol. 16. 
North Holland Publishing Company, Amsterdam.

NORTHFIELD, D.W.C. (1973). Head Injury. In: The Surgery of the Central Nervous System. Northfield D.W.C. Blackwell Scientific Publications, Oxford.

PATTERSON, J.H., McKISSOCK, W.A. (1956). A clinical survey of intracranial angiomas with special reference to their mode of progression and surgical treatment. A report of 110 cases. Brain 79: 233-266.

PENFIELD, W.G. and ERICKSON, T.C. (1941). Epilepsy and Cerebral localisation.
Charles C. Thomas, Springfield, Illinois, pp 623.

PENFIELD, W.G., JASPER, H.H. (1954). Epilepsy and the Functional Anatomy of the Human Brain. Little Brown, Boston. pp 896.

PRIOR, P.F., LEGG, N.J. and SCOTT, D.F. (1973). Epilepsy following Intracranial Surgery. In: Prevention of Epilepsy and its consequences: Proceeding of the Fifth European Symposium on Epilepsy. Ed. Parsonage, M.J. International Bureau of Epilepsy, London.

RAPPORT, R.L., PENRY, J.K. (1973). A survey of the attitudes towards the pharmacological prophylaxis of post-traumatic epilepsy, J. Neurosurg. 38: 159-166.

RUSSELL, W.R. (1951). Disability caused by brain woulds. Review of 1166 cases. J. Neurol. Neurosurg. Psychiat. 14: 35-39.

WADA, J.A., OSAWA, T. (1976). Spontaneous recurrent seizure state induced by daily electric amygdaloid stimulation in Senegalese baboons (Papio papio). Neurology, 26: 253286. 